\title{
Egerton University Students' Level of Awareness of the Risks of Engaging in Sexual Behaviours and Attitude Towards Effectiveness of Counselling Services
}

\author{
Janet C. Soy* $\quad$ Prof. Teresia Njonge Dr. B.E.E. Omulema \\ Department of Psychology, Counselling and Educational Foundations, Egerton University P.O Box 536-20115, \\ Egerton, Kenya
}

\begin{abstract}
Young people form a large number of the population worldwide. A large part of this population group lives in developing countries. They are at higher risk of involving in risky sexual behaviours. These risky sexual behaviour sway youths to numerous sexual and reproductive health repercussions such as unwanted pregnancies, unsafe abortions, sexually transmitted infections (STIs) including HIV and AIDS. Globally, awareness about the spread of HIV and a positive attitude on safe sexual practices has a serious control over the prevention of HIV and AIDS. The purpose of this study was to determine students' level of awareness of risky sexual behaviours and attitudes towards the effectiveness of counselling services. To achieve this purpose, descriptive design was used. The target population was 14,578 undergraduate students from Egerton University. The accessible population was 12,462 students from nine sampled faculties at Egerton University, Njoro Campus. The sample was 375 respondents, however, 351 respondents were included in data analysis as some were rejected due to incomplete responses and missing data. Probability Proportionate to size, stratified sampling, simple random sampling, and purposive sampling methods were used to select the participating faculties and respondents. Seven student counsellors were purposively sampled too as key informants since they directly counselled students daily. A questionnaire and interview schedule were used to collect data. A pilot study was carried out at Laikipia University-Main Campus and 37 students participated to establish the reliability of the questionnaire. In the study, the reliability coefficient of 0.78 was established using Cronbach alpha. The collected data were analysed using both descriptive and inferential statistics (Pearson Correlations coefficients, Multivariate Regression, and t-test). Statistical Package for Social Sciences (SPSS) version 22.0 aided in data analysis. The study established that both levels of awareness of risky sexual behaviours and students' attitudes have a significant association with the effectiveness of counselling at 0.05 significant levels. Following these findings, the study recommends the development of effective intervention programmes and sensitisation programmes that inform students about the effectiveness of counselling services to enhance the utilization of these services in the prevention of unwanted pregnancies, unsafe abortions, sexually transmitted infections and drug abuse.
\end{abstract}

Keywords: Level of awareness, Students' attitude, Risky sexual behaviours, effectiveness of counselling services DOI: $10.7176 / \mathrm{JEP} / 11-9-20$

Publication date:March $31^{\text {st }} 2020$

\section{Introduction}

Globally, there is roughly 1.7 million youth with $86 \%$ living in developing countries. More than half of the population comprises of youths less than 25 years old. (UNFPA the State of World Population, 2011). These youths are found to be at a high risk of practicing risky sexual behaviours (Alamrew, Bedimo, \& Azage, 2013). The youths seem to be tangled in risky sexual behaviour e.g. early sexual debut, having multiple sex partners, and non-use of condoms. This makes them vulnerable to numerous health problems such as sexually transmitted infections (STIs), human immunodeficiency virus (HIV) and acquired immune deficiency syndrome (AIDS). (Agardh, Cantor-Graae \& Ostergren 2012). Worldwide 45\% of new HIV infections have been found from statistics to be occurring among youths ages 15-24. Furthermore, the use of substances during sex may lead the young people to engage in risky sexual behaviours due to disruption of their judgment. (Woolf-King, Rice, Truong, Woods, Jerome \& Carrico, 2013). The use of Alcohol is cited by several studies as one of the common factors which escalate the risk of HIV acquisition (Woolf-King \& Maisto, 2011). Risky sexual behaviours engaged in such situations increase the risk of youths to acquire HIV. In this case, tackling the issue of sexual and nonsexual risk behaviours among young peoples is vital in decreasing the risk of HIV and other STI diseases (Lou, GAO, Li, $\&$ Zabin, 2012). Without appropriate age and organization targeted interventions in existence, certain behaviours and deeds of the students may put them at a greater risk of STI including HIV and unwanted pregnancy (GlenSpron 2015).

The risky sexual behaviours of youth position them to long-term and short-term worries. Their health has a major influence on national development. According to Fikree, Lane, Simon, Hainsworth \& MacDonald, (2017), youths add to high maternal mortality in Africa with up to $40 \%$ of all maternal deaths in some countries. With four million unsafe abortions yearly, 25\% occur among youths aged 19-25 years. While plans must be tailored to the 
progressive needs of this age group and their social settings, effective approaches need to be multifaceted. This needs operational interventions that will focus on multiple ranges of health risks helping in the advancement of sound reproductive health among youths. (Scott, Wildsmith, Welti, Ryan, Schelar, Steward-Streng, 2011). Wamoyi, Fenwick, Urassa, Zaba, and Stones, (2011) found in the study on parent-child communication about sexual and reproductive health in rural Tanzania, that parents and family were critical elements in programs directed at reducing risky sexual behaviours in youths. They noted that even as parents focus on abstinence, the key goal of sexual reproductive health education should be mentorship of youths capable of using an agency in the management of their sexual reproductive health (Wamoyi et al 2011). In the evaluation of other regions around the world, young women in Sub-Saharan Africa rank top in regards to the risk of death due to unsafe abortions with half of all general deaths happening in women less than the age of 25 years (De Cock, Rutherford \& Akhwale, 2014). It was also found that $60-80 \%$ of African women infected with the virus had been through sexual intercourse. These negative concerns in reproductive health occur presently among young people in Sub-Saharan Africa born in social waves of poverty and HIV/AIDS. (UNICEF, 2011). Gavin, Catalano, David-Ferdon, Gloppen, and Markham, (2010) argue that helpful youth development programs are vital in the advancement of adolescent and youths sexual and reproductive health.

Half of all new HIV infections are in youths while one quarter to half of the teenage girls become mothers before 18 years. It is observed that by the age of 15 years, most teenage girls reach sexual maturity with possible exposure to the risk of sexually transmitted diseases and unplanned pregnancies. In Kenya, the Kenya AIDS Indicator Survey in 2012 revealed that female youth had an advanced probability of HIV infection than their male colleagues. Continued resource distribution in Kenya towards effective plans in prevention and treatment approaches is vital in safeguarding the sexual and reproductive health of youths. (Gavin et al 2010). According to Eaton (2012), the level of risky sexual behaviours and the spread of STIs is high consequently because of the scarcity of information on youths' sexuality. Awareness about the spread of HIV and a positive attitude on safe sexual practices has a serious sway on the prevention of HIV and AIDS. Studies on public awareness of HIV and AIDS and positive attitudes towards counselling usually aim at giving information geared to how much individuals know about HIV and AIDS, factors related to this information and attitudes towards the effectiveness of counselling. Regardless of the fact that both awareness of HIV and AIDS and positive attitudes are among the most vital tools in the fight against HIV and AIDS, research around the world has often recognized gaps in youth knowledge of HIV transmission and high-risk behaviours and susceptibility to HIV infection (Mojelantle, Keetile, Bainame \& Nkawana, 2014).

\subsection{Statement of the Problem}

University students in Kenya are well-informed about risky sexual behaviours. They begin learning about risky sexual behaviours back in their elementary and secondary school education. Unfortunately having risky sexual behaviours' understanding has not interpreted to behaviour change. Students are stated to be involved in risky sexual behaviour that ranges from multiple sexual partners to unreliable condom use. Even though information on HIV/STIs towards sexual risk and positive attitude are among the most significant tool in the battle against HIV/STIs, research around the world has repeatedly acknowledged gaps in young people's knowledge of HIV/AIDs transmission and high-risk behaviours and susceptibility to HIV/STIs infection. On the other hand, counselling services are improving every day and university students are in need, but the amount of guidance and counselling is very low despite many cases of HIV, STI, unwanted pregnancy and illegal abortion. Therefore, this study seeks to establish the students' level of awareness of risky sexual behaviours and attitudes towards the effectiveness of counselling services.

\subsection{Purpose of the Study}

This study aimed at establishing students' level of awareness of risky sexual behaviours and attitudes towards the effectiveness of counselling services.

\subsection{Research Hypotheses}

$\mathrm{H}_{01}$ There is no statistically significant relationship between the students' level of awareness on risky sexual behavior and effectiveness of counselling services.

\subsection{LITERATURE REVIEW}

2.1. Students' Level of Awareness of Risky Sexual Behaviours and Effectiveness of Counselling Services Being familiar with the knowledge of risky sexual behaviour is a vital aspect in the lives of university students with a direct consequence on the completion of university studies and advancing to industrious adults. The World Health Organization estimates that every day, more than 1 million people acquire an STI. (WHO, 2015). It is difficult to quantify the proportion of these infections which go undiagnosed and untreated, which is part of the problem of understanding and managing untreated infections. Empirical studies suggest that less than $50 \%$ of 
untreated chlamydia spontaneously resolves without treatment while several viral STIs including HIV, herpes, hepatitis B and human papillomavirus are incurable. Modelling studies have estimated that if sex partners are not treated simultaneously $19.4 \%$ of patients diagnosed with chlamydia and $12.5 \%$ of those with gonorrhoea will be re-infected. Symptoms can trigger help-seeking and have been reported as the most common reason for the attendance of counselling and further healthcare (Balfe, Brugha, O'Connell \& Vaughan 2010). Untreated infections can cause long-term health problems exacerbating the burden of STIs globally. Accessing screening services requires individuals to seek help or at least engage with opportunistic STI testing. (Low, Heijne, Herzog \& Althaus 2014).

In Taiwan, professionals such as therapists, counsellors, psychologists, medical personnel and social workers work to address various issues related to sexuality through counselling and therapy sessions (Hsu 2010). Counselling is an important public health practice in the challenging task of breaking the chain of transmission of sexually transmitted diseases (STDs), HIV and AIDS. It is based on three basic tasks: providing information, assessing risks, and providing emotional support. (Taegtmeyer, Davies, Mwangome, van der Elst, Graham, Price 2013). In Brazil and worldwide, counselling is an essential strategy in the fight against STD, HIV, and AIDS because of the low cost of implementation and its potential effectiveness. (Cawley, Wringe, Slaymaker, Todd, Michael, Kumugola, 2014). In addition to the preventive measures available (condoms, post-exposure prophylaxis), counselling is a method to address these diseases. (Tromp, Siregar, Leuwol, Komarudin, van der Ven, van Crevel, et al. 2013). Counselling has particular applicability in situations of infection risk through sexual exposure. Educational activities can improve health care quality and can be used at several different times in health facilities, not just at the offer for HIV testing. (Sanga, Kapanda, Msuya, \& Mwangi 2015). The Brazil Ministry of Health established testing and counselling centers to offer diagnosis and counselling based on the values of voluntariness, confidentiality, anonymity, speed, and resolution of HIV diagnosis. (Silva, Figueiredo, Medeiros, Oliveira, Vieira \& Prado 2013). In the late 1990s, the Ministry of Health initiated decentralizing STD prevention activities for primary health care. This has become a significant area of prevention and care of these diseases because it is a priority component of the Brazilian government control of the HIV epidemic. One of the main concerns of primary care is the development of preventive actions for STD in the individual and collective contexts. (Sanga, Kapanda, Msuya, \& Mwangi 2015). Providing youth with basic healthy sexual behaviour enables them to protect themselves from becoming infected. Young people are often particularly vulnerable to risky sexual behaviour. Acquiring knowledge and skills encourages young people to avoid or reduce behaviours that carry a risk of STI infection and unintended pregnancies. Even for young people who are not yet engaging in risky behaviour, behaviour education is important for ensuring that they are prepared for situations that will put them at risk as they grow older (Hindin 2009).

Awareness of risky sexual behaviours could assist youths in delaying their initiation into sexual activities and protect those who are already involved in sexual activities. However, despite these government initiatives including the establishment of Guidance and Counselling programme in secondary schools and universities, there is relatively limited information about the level of awareness of risky sexual behaviour of students about contraceptive use in the prevention of Sexually Transmitted Diseases. Hence this study sought to determine the level of awareness of risky sexual behaviour and attitude towards the effectiveness of counselling services.

\subsection{Theoretical Framework}

The proposed study was anchored on the Theory of Planned Behaviour (TPB) and the health belief model (HBM). The HBM were developed in the 1950s by social psychologists (Sharma and Romas, 2012; Rosenstock, 2005; Becker, 1974; Hochbaum, 1958). The Theory of Planned Behaviour (TPB) was preceded by the Theory of Reasoned Action in 1980. The theory of reasoned behaviour was used to predict an individual's intention to engage in a given behaviour in a specific time and place. The theory was intended to explain how individual self-control ability influences people's behaviour. The underlying component of TPB is the behavioural intent. Behavioural intentions are further influenced by the attitude about the likelihood that the behaviour will result in the expected outcome and that the subjective evaluation of the risks and benefits of that outcome. TPB was postulated and developed by Ajzen in 1988. The theory focuses on how human actions are guided and how they can be measured. TPB predicts the likelihood of a given behaviour based on behavioural intention. TPB assumes that human beings behave wisely. They take into account the available information and, implicitly or explicitly, consider the implications of their actions. The theory further postulates that a person's intention to engage or not to engage in a certain behaviour is the most important and immediate determinant of that action (Ajzen, 2014; Linder, Harper, Jinhong, \& Woodson-smith, 2013). The theory of planned behaviour further states that intentions are a function of three basic determinants. The first determinant is personal in nature (attitudes). The second determinant reflects one's social influence (subjective norms). The last determinant deals with issues of control (behavioural control).

In general, people engage in a given behaviour when they evaluate it positively, when they experience social pressure to do it and when they believe that they have means and opportunities to do so (Ajzen, 2014; Linder et al., 2017). According to TPB, individuals who have a positive attitude towards abstaining from sexual intercourse 
and being faithful to one partner are likely to refrain from participating in casual sexual relations. Furthermore, when individuals are always mindful about having safe sex or not engaging in casual sexual relations with someone they just encounter, they are unlikely to engage in risky sexual behaviour. By refraining from having sexual relations with someone who is much older than themselves, or for money, goods or favours, they protect themselves from contracting sexually transmitted diseases. Those who perceive that they receive social support from important and responsible people are also likely to behave accordingly because they are convinced that they can have responsible sexual behaviour (Fisher, 1997).

TPB is one of the most widely cited and applied behavioural theories. It is one of the closely inter-related families of theories that adopt a cognitive approach to explaining behaviours that centre on individuals' attitudes and beliefs. Using the theory to explain and predict the likely behaviour may, however, be a useful method for identifying particular determinants of behaviour that could be targeted for change. The theory makes reference to both awareness of risky sexual behaviour and student's attitude which are the independent variables of this study. Therefore, it compensates for what is lacking in the HBM. Figure 1 provides the relationship between different determinants of behaviour as postulated by TPB. The Health Belief Model, developed in the 1950s, is the second model that attempts to provide a theoretical explanation for sexual behaviours (Sharma and Romas, 2012; Rosenstock, 2005; Becker, 1974; Hochbaum, 1958). The HBM has successfully been used to encourage the use of condom and seat belt as well as to promote medical compliance, health screening, and other health-related behaviours. It is a cognitive model which posits that behaviour is determined by individuals' belief about threats to their wellbeing. It also posits that the effectiveness and outcomes of particular actions or behaviours determine individual behaviour. Some constructions of the model feature the concept of self-efficacy (Bandura, 1997) alongside beliefs about actions. The beliefs are further supplemented by additional stimuli referred to as 'cues to action' which trigger actual adoption of behaviour.

The perceived threat is at the core of the HBM. Perceived threat determines one's readiness to engage in a given action. The readiness to engage in a given action depends on individual beliefs on the perceived vulnerability to a particular threat as well as the seriousness of the expected consequences. The perceived benefits associated with behaviour (effectiveness in reducing the threat) are weighed against the perceived costs and negative consequences that may result from it (perceived barriers). The negative consequences of a given behaviour can be the side effects of treatment and, therefore, it is important to establish the overall extent to which behaviour is beneficial. The individual's perceived capacity to adopt the behaviour (their self-efficacy) is also a key component of the model. Lastly, the HBM identifies internal and external cues to action which influence behaviour. Internal cues to action are symptoms of ill health whereas external cues to action can either be media campaigns or other types of information. These cues affect the perception of threats and can trigger or maintain behaviour.

2.3. Conceptual Framework

\begin{tabular}{|c|c|c|}
\hline Independent Variables & Dependent Var & \\
\hline $\begin{array}{l}\text { Awareness of risky sexual } \\
\text { behaviours } \\
\text { - Sex at early age } \\
\text { - Multiple sex partners } \\
\text { - Unprotected sex behaviours } \\
\text { - Sex under influence of } \\
\text { - Alcohol and Drug Abuse } \\
\text { - Awareness of policies } \\
\text { Student Attitude on } \\
\text { - Counselling and testing }\end{array}$ & $\begin{array}{l}\text { - Campus environment } \\
\text { - Religiosity } \\
\text { - Culture } \\
\text { - Parenting } \\
\text { - Prior sexual exposure }\end{array}$ & $\begin{array}{l}\text { Effectiveness of } \\
\text { counselling services } \\
\text { - Behaviour change } \\
\text { - Help Seeking } \\
\text { Behaviour }\end{array}$ \\
\hline
\end{tabular}

Figure 2.1: Conceptual framework

\subsection{Research Methodology}

This study was descriptive in approach and utilized the survey design. Descriptive survey design is used to designate any research activity in which the researcher gathers data from a sample of a population for the purpose of examining characteristics, opinions or interactions of that population (Fraenkel \& Wallen, 2000). Descriptive 
design was also selected because of its high degree of representativeness, and the ease with which the researcher obtained the respondents' characteristics. Descriptive survey designs are not only useful in collecting data from large numbers of people but also generally involve the use of questionnaires (Barnyard \& Grayson, 2000). This design was suitable for study because variables under study, students' level of awareness of risky sexual behaviours, attitudes and effective counselling had already occurred, and therefore the researcher was not able to manipulate them. The study was carried out at Egerton University, Njoro Campus in Njoro Sub-County, Nakuru County. The County is located in Rift Valley region of Kenya. The study sample was selected using probability proportionate to size, purposive, stratified sampling and simple random sampling to obtain the required sample of the students in each faculty. In addition, the study purposively selected 7 student counsellors.

Data of the study was collected using the questionnaires made mostly of closed-ended questions. The questionnaire was reviewed by the researcher's supervisors from the Department of Psychology, Counselling and Educational Foundations in assessing and verifying the content, construct and face validity of instruments. The data was analyzed using both descriptive and inferential statistics. Pearson's Correlation Co-efficient (r) and regression was used to determine relationship between the two variables at 0.5 significant level.

\subsection{Results and Findings}

The study examined relationship between students' level of awareness towards risky sexual behaviours and effectiveness of counselling services. Data on level of awareness was elicited using the students' questionnaire. In order to achieve this objective, correlation analysis and regression analysis were carried out.

The hypotheses were tested by establishing the relationship between students' level of awareness of risky sexual behaviour and effectiveness of counselling services. Pearson's Correlation Co-efficient (r) was used to determine the strength and the direction of the relationship between the two variables. Table 4.1 shows a correlation coefficient matrix of frequency of level of awareness of risky sexual behaviour; and effectiveness of counselling services.

Table 1: Correlation Analysis of Level of Awareness of Risky Sexual Behaviour and Effectiveness of Counselling Services

\begin{tabular}{llrr}
\hline & & $\begin{array}{c}\text { Level of } \\
\text { awareness }\end{array}$ & $\begin{array}{c}\text { Effectiveness of } \\
\text { Counselling Services }\end{array}$ \\
\hline Level of Awareness & Pearson Correlation & 1 & $.276^{* *}$ \\
& Sig. (2-tailed) & .000 \\
Effectiveness of Counselling & $\mathrm{N}$ & 351 & 351 \\
& Pearson Correlation & $.276^{* *}$ & 1 \\
& Sig. (2-tailed) & .000 & \\
& $\mathrm{~N}$ & 351 & 351 \\
\hline
\end{tabular}

**. Correlation is significant at the 0.05 level (2-tailed). $(\mathrm{r}=0.276, \mathrm{p}>0.05)$

Table 1 indicates that the level of awareness of risky sexual behaviour with effectiveness of counselling services was positively correlated $(r=0.276, p=.000, p<0.05)$. The positive correlation between level of awareness and effectiveness of counselling services suggests that that the higher the level of awareness of risky sexual behaviour the more effectiveness of counselling services in the university. Since $p$ value in this case is also equal to 0.000 which is less than the significance level of 0.05 . Therefore, we reject the null hypothesis that there is no significant relationship between the student's level of awareness and effectiveness of counselling services and accept the alternative hypothesis that there is a significant relationship between the students' level of awareness and effectiveness of counselling. This implies that there is a significant positive relationship between student level of awareness and effectiveness of counselling services

The results obtained from Person's correlation were counter-checked using Regression model in order to establish any significant difference in the level of awareness to the effectiveness of counselling services.

Table 2: Analysis of Variance for Test of Significance of the Regression

\begin{tabular}{llrrrrr}
\hline Model & & Sum of Squares & Df & Mean Square & F & Sig. \\
\hline \multirow{3}{*}{1} & Regression & 879.239 & 1 & 879.239 & 28.890 & $.000^{\mathrm{b}}$ \\
& Residual & 10621.427 & 349 & 30.434 & & \\
& Total & 11500.667 & 350 & & & \\
\hline
\end{tabular}

a. Dependent Variable: effectiveness of counselling

b. Predictors: (Constant), level of awareness 
Table 3: Coefficients of Level of Awareness of Risky Sexual Behaviour

\begin{tabular}{|c|c|c|c|c|c|c|}
\hline \multirow[t]{2}{*}{ Model } & & \multicolumn{2}{|c|}{ Unstandardized Coefficients } & \multirow{2}{*}{$\begin{array}{c}\text { Standardized } \\
\text { Coefficients } \\
\text { Beta }\end{array}$} & \multirow[t]{2}{*}{$\mathrm{T}$} & \multirow[t]{2}{*}{ Sig. } \\
\hline & & B & Std. Error & & & \\
\hline \multirow[b]{2}{*}{1} & (Constant) & 10.546 & 1.641 & & 6.428 & .000 \\
\hline & Level of awareness & .473 & .088 & .276 & 5.375 & .000 \\
\hline
\end{tabular}

a. Dependent Variable: effectiveness of counselling services

From Table 3, $\mathrm{y}$ is the dependent variable and $\mathrm{x}_{1}$ is the students' level of awareness. Level of awareness had unstandardized coefficient (B) of 0.473 . This meant that increasing values of level of awareness by one unit it increased the effectiveness of counselling services by 0.473 when other independent variables were held constant. The regression equation of level of awareness on effective counselling services then becomes;

$$
y=10.546+0.473 x_{1}
$$

This finding concur with the World Health Organization which documented that per the estimates of every day, more than 1 million people acquire a STI, hence become difficult to quantify the proportion of these infections which go undiagnosed and untreated, but when individual is aware of these symptoms it trigger help-seeking behaviour which have been reported as the most common reason for attendance of counselling services and further healthcare (Balfe, Brugha, O’Connell \& Vaughan 2010).Effectiveness of Counselling Services is an important public health practice in the challenging task of breaking the chain of transmission of sexually transmitted diseases (STDs), HIV and AIDS. It is based on three basic tasks: providing information, assessing risks, and providing emotionally support. (Taegtmeyer, Davies, Mwangome, van der Elst, Graham, Price 2013). Similarly, in Brazil and worldwide, counselling is an essential strategy in the fight against STD, HIV, and AIDS because of the low cost of implementation and its potential effectiveness. (Cawley, Wringe, Slaymaker, Todd, Michael, Kumugola, 2014).

Furthermore providing the youth with basic healthy sexual behaviour enables them to protect themselves from becoming infected. Young people are often particularly vulnerable to risky sexual behaviour. Acquiring knowledge and skills encourages youths to avoid or reduce behaviours that carry a risk of STI infection and unintended pregnancies. Even for youths who are not yet engaging in risky behaviour, behaviour education is important for ensuring that they are prepared for situations that will put them at risk as they grow older (Hindin, 2009). Consistent with this statement, effective counselling include behavioural interventions which are defined as interventions that are tailor-made to reduce high-risk sexual behaviour such as unprotected sex and multiple partners, and to improve acceptance of voluntary counselling and testing (VCT). Voluntary testing and counselling is known to change behaviour (Corbett 2007). Participants in our study reported high awareness of risky sexual behaviour. This finding replicates the observation made by Mwamwenda (2013) in his study among high school students in Kenya. However, other previous studies have observed disconnect between HIV/AIDS level of knowledge and sexual behaviour (e.g. Lake Victoria Basin Commission, 2010; Othero et al., 2009). In the study by Othero and colleagues, for example, despite their high HIV/AIDS knowledge, their participants admitted to engaging in risky sexual behaviour. Their investigation concludes that there is need for promoting peer education programmes, as a way of combating the spread of HIV/AIDS (Othero et al. 2009). Hence, creating awareness of guidance and counselling among university students in Kenya is critical in assisting them to overcome challenges of risky sexual behaviour that they encounter while on campus.

In this analysis, the study sought to test the hypothesis that stated that there is no statistically significant relationship between level of awareness of risky sexual behaviour and effectiveness of counselling services. The current study rejects the null hypothesis and concludes that there is statistically significant relationship between level of awareness of risky sexual behaviour and effectiveness of counselling services.

\subsection{Summary of the Study Findings}

The main objective of the study was to determine the level of awareness of Risky sexual behaviour and effectiveness of counselling services in Egerton University, Kenya. The findings of the study revealed that there existed a significant relationship between the level of awareness and effectiveness of counselling services.

\subsubsection{Level of Awareness of Risky Sexual Behaviour and Effectiveness of Counselling Services}

The findings of the study revealed that there existed a significant relationship between the level of awareness and effectiveness of counselling services $(r=0.276, p=.000, p<0.05)$. The positive correlation between level of awareness and effectiveness of counselling services suggests that that higher the level of awareness of risky sexual behaviour the more effectiveness of counselling services in the university. Level of awareness had unstandardized coefficient (B) of 0.473 . This meant that increasing values of level of awareness by one unit increased the effectiveness of counselling services by 0.473 when other independent variables were held constant. In support of past studies, the current study established that there was significant positive relationship between the level of awareness and effectiveness of counselling services 


\subsection{Conclusion and Recommendation}

It was concluded that the students' level of awareness of risky sexual behaviour had positive association with respondents' effectiveness of counselling at Egerton University, Njoro Main Campus. Counsellors, psychologists and medical personnel work to address various issues related to sexuality through counselling and therapy sessions. It was therefore recommended that there is need to continue to develop effective intervention programmes and sensitisation programmes to enhanced level of awareness of students on risky sexual behaviour and developed effectiveness of counselling services in order to enhance fully utilization of these services in the prevention of unwanted pregnancy, unsafe abortions, drug abuse and sexual transmitted infections in our Kenyan universities.

\subsection{Recommendations for Further Research}

The subject of students' level of awareness of risky sexual behaviour and effectiveness of counselling services has attracted limited research attention in the country. This study can be extended to other private universities of other East African countries. Ideally multiple studies can help in identifying similarities and difference in the region. A study can be carried out in the other learning institutions to analyze the students' level of awareness of risky sexual behaviour. Comparison of results with the existing study can help in understanding their influence on risky sexual behaviour of other sectors. Therefore, further research can be done to capture other communities or Universities in Kenya to establish whether the findings will be replicated. Further research could also be done on Influence of risky sexual behaviour and attitude towards effectiveness of counselling services.

\section{References}

Agardh, A., Odberg-Pettersson, K., \&Östergren, P. (2012). Experience of sexual coercion and risky sexual behaviour among Ugandan university student. BMC Pub Health.

Alamrew, Z.M., Bedimo, \&Azage, M. (2013). Risky sexual practices and associated factors for HIV/AIDS infection among private college students in Bahir Dar City, Northwest Ethiopia, ISRN Public Health, vol. 2013, Article ID 763051

Ajzen, I. (2014).Behavioural interventions based on the Theory of Planned Behaviour. Retrieved 12 Sept. 2018 fromhttps://www.researchgate.Behavioral-Interventions-Based-on-the-Theory-of-PlannedBehavior.pdf?origin=publication_detail

Balfe, M, Brugha R, O’Connell E, Vaughan D. (2010). Triggers of self-conscious emotions in the sexually transmitted infection testing process. BMC Res, Notes 3:229.

Becker, M. H. (1974). The Health Belief Model and Personal Health Behaviour. Thorofare, NJ: Charles B. Slack.

Corbett, E.L. (2007). HIV incidence during a cluster-randomized trial of two strategies providing voluntary counselling and testing at the workplace, Zimbabwe, 483-489.

Cawley C, Wringe A, Slaymaker E, Todd J, Michael D, Kumugola Y, et al.(2014). The impact of voluntary counselling and testing services on sexual behaviour change and HIV incidence: observations from a cohort study in rural Tanzania. BMC Infect Dis; 14:159-69.

De Cock, K.M., Rutherford, G.W., Akhwale, W. (2014).Kenya AIDS Indicator survey 2012. Journal of Acquire Immune Deficiency Syndrome. 66:S1-S2. doi: 10.1097/QAI.0000000000000152

Eaton, D. K., Kann, L., Kinchen, S., Shanklin, S., Flint, K. H., Hawkins, J., \& Wechsler, H. (2012). Youth risk behaviour Surveillance-United States, Morbidity and Mortality Weekly Report: Surveillance Summaries, 61, $1-162$.

Fikree, F.F., Lane, C., Simon, C., \&Hainsworth, G. (2017). MacDonald P. Making good on a call to expand method choice for young people-Turning rhetoric into reality for addressing Sustainable Development Goal Three. Reproductive Health Journal.

Gavin, L.E., Catalano, R.F., David-Ferdon, C., Gloppen, K.M, \&Markham, C.M. (2010). A review of positive youth development programs that promote adolescent sexual and reproductive health. $J$ Adolesc Health. 46, S75-S91. doi: 10.1016/j.jadohealth.2009.11.215

Glen-Spyron, C. (2015). Risky Sexual Behavior in Adolescence. Available at: www.Bellavidacentre. Co.za. Accessed on 22Oct 2015.

Hindin, M.J., \& Fatusi, A.O. (2009). Adolescent sexual and reproductive health in developing countries: An overview of trends and interventions. International Perspectives on Sexual and Reproductive Health, 35(2), 58-62.

Hochbaum, G. (1958). Public participation in medical screening programs: Socio-psychological study. Washington, D.C: Public Health Service Publication

Hsu, Y. T. (2010). “The Process of Counselors' Sexuality and Gender Awareness - Counselor's Sexuality and Gender Training as an Example." (In Chinese.) Unpublished Thesis, Tamkang University.

Linder, A. D., Harper, A., Jinhong, J., \& Woodson-smith, A. (2017). Ajzen's theory of planned behaviours attitude and intention and their impact on physical activity among college students enrolled in lifetime fitness courses. College Student Journal, 51, 550-560. 
Lou, X., Tu, C., GAO, E. N., Li, \&Zabin, L. S. (2012). “The relationship between sexual behavior and nonsexual risk behaviors among unmarried youth in three Asian cities," Journal of Adolescent Health, vol. 50

Low, N., Heijne, J.C.M., Herzog, S.A, Althaus, C.L. (2014). Reinfection by untreated partners of people treated for Chlamydia trachomatis and Neisseria gonorrhoeae: mathematical modelling study. Sex Transm Infect: 90:254-6

Majelantle, R. G., Keetile, M., Bainame, K., \&Nkawana, P. (2014). Knowledge, Opinions and attitudes towards HIV and AIDS among youth in Botswana. Journal of Global Economics, 2, 1-7.

Mwamwenda, T. S. (2014). Education level and HIV/AIDS knowledge in Kenya, Journal of AIDS and Research, $6,28-32$.

Othero, D. M., Aduma, P. \&Opil, C. O. (2009). Knowledge, attitudes and sexual practices of university students for advancing HIV education. East Africa Medical Journal, 86, 11-5.

Rosenstock, I. M. (2005). Why people use health services. Milbank Memorial Fund Quarterly, 44, 94-124.

Sanga Z, Kapanda G, Msuya S, Mwangi R. (2015). Factors influencing the uptake of voluntary HIV counselling and testing among secondary school students in Arusha City, Tanzania: a cross sectional study. BMC Public Health. 15, 452-60

Scott, M.E., Wildsmith, E., Welti, K., Ryan, S., Schelar, E., \&Steward-Streng, N.R., (2011). Risky adolescent sexual behaviours and reproductive health in young adulthood. Perspective Sex Reproductive Health. 43,110-118. doi: 10.1363/4311011.

Sharma, M., \& Romas, J. A. (2012). Theoretical foundations of health education and health promotion. London, UK: Jones and Bartlett Learning.

Taegtmeyer M, Davies A, Mwangome M, van der Elst EM, Graham SM, Price MA, et al. (2013). Challenges in providing counselling to MSM in highly stigmatized contexts: results of a qualitative study from Kenya. PLoS One. 8: 64527

Tromp N, Siregar A, Leuwol B, Komarudin D, van der Ven A, van Crevel R, et al. (2013). Cost-effectiveness of scaling up voluntary counselling and testing in West-Java, Indonesia. Acta Med Indones. 2013; 45:17-25

UNICEF \& WHO. (2011). Young People and HIV/AIDS: Opportunity in crisis. Progress for children: Achieving the MDGs with equity. New York, NY: UNICEF

UNFPA the State of World Population. (2011). "People and possibilities in a world of 7 billion".

Wamoyi, J., Fenwick, A., Urassa, M., Zaba, B., \&Stones, W. (2011). Parent-child communication about sexual and reproductive health in rural Tanzania: implications for young people's sexual health interventions. Reproductive Health. doi: 10.1186/1742-4755-7-6

WHO. (2015). Global HIV/AIDS Response: Epidemic update and health sector progress towards Universal Access, Progress Report 2011. Retrieved from http://www.afro.who.int/en/hiv/aids-publications/3439global-hivaids-response-progress-report-2011.html

Woolf-King, S.E. Rice,T. M., Truong,H.-H. M., Woods,W. J., Jerome, R. C \&Carrico, A. W.(2013). "Substance use and HIV risk behavior among men who have sex with men: the role of sexual compulsivity," Journal of Urban Health, vol. 90.

Woolf-King,S.E., \& S. A. Maisto, (2011).“Alcohol use and high-risk sexual behavior in Sub-Saharan Africa: a narrative review," Archives of Sexual Behavior, vol. 40. 